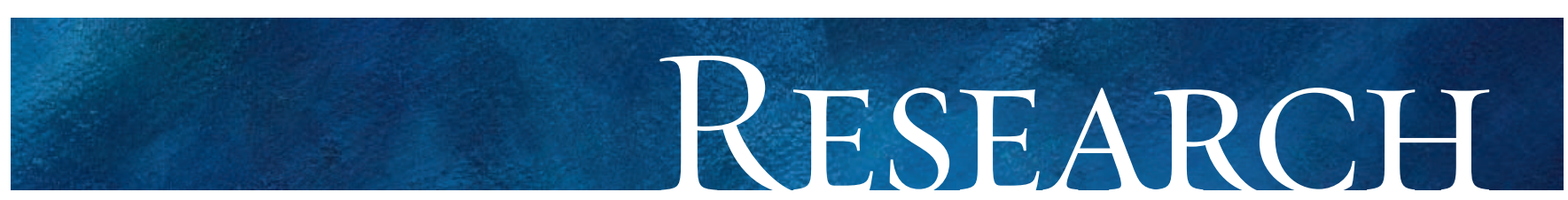

Research letter

\title{
Changes in illicit opioid use across Canada
}

\author{
Benedikt Fischer, Jürgen Rehm, Jayadeep Patra, Michelle Firestone Cruz
}

$\infty \quad$ See related article page $\mathbf{3} 395$

$\mathrm{F}$ or almost a century, heroin addiction has been a core element of the illicit drug use problem in Canada. ${ }^{1,2}$ According to recent data, there are an estimated I25 000 injection drug users in Canada, most of whom use heroin and cocaine. ${ }^{3}$ Heroin addiction is associated with a variety of harms, including death, morbidity and crime. There are many examples of these harms: the number of overdoserelated deaths in British Columbia rose dramatically from 39 to 33I between 1988 and $1993 ;^{4}$ the majority of new cases of hepatitis $\mathrm{C}$ in Canada are related to illicit drug use ${ }^{5}$ and most heroin addicts are involved in regular criminal activity. ${ }^{6} \mathrm{Con}-$ siderable public resources are expended on heroin addiction. Canadian law enforcement agencies direct substantial expenditures to prevent heroin importation and distribution albeit with limited success. ${ }^{7,8}$ On the health care side, the number of people receiving methadone maintenance treatment (the primary treatment response for heroin addiction) has increased 5 times since the mid-rggos, to about 25000 spaces across Canada. ${ }^{9-11}$ Furthermore, alternative treatment options are in development, including buprenorphine maintenance and medical heroin treatment. ${ }^{3,12,13}$ In the past several years, there have been isolated reports of substantially increased levels of prescription opioid abuse in Canada, the United States and other jurisdictions. ${ }^{14-16}$ However, until now, its impact on usage patterns among street drug users in Canada has been unclear and not systematically documented.

The multisite OPICAN cohort (formed through communitysupported outreach and snowball recruitment methods and comprising regular illicit opioid users who were not receiving treatment at the time of recruitment) was established in $200 \mathrm{I}$ with a baseline sample of 679 participants to assess current opioid use patterns and related social and health indicators. ${ }^{17}$ The participants were recruited from 7 Canadian cities (Vancouver, Edmonton, Toronto, Montréal, Québec, Fredericton and St. John) and were assessed most recently in 2005. The OPICAN study sites were chosen to produce a cross-section of existing profiles of illicit opioid use in large and midsized cities across Canada and were determined by local feasibility of the study protocol. Between $200 \mathrm{I}$ and the assessment in 2005, the longitudinal component of the study had a follow-up rate of $58.6 \%$. Participants who were lost to follow-up were replaced with newly recruited participants to ensure large enough samples for hypothesis testing. Local samples of populations in Fredericton and St. John were added in 2005. All assessments of participants throughout the study were conducted by means of a standardized protocol, which included an interview, a clinical assessment (e.g., for psychiatric symptoms) and biological measures (e.g., saliva antibody tests for HIV and hepatitis C virus). Ethics approval for each component of the study was obtained from local institutions. The Research Ethics Board of the Centre for Addiction and Mental Health provided the first approval in 200I. The data reported here are based on a sample of 585 participants from the 2005 follow-up and exclude those who were involved in methadone maintenance treatment before assessment (to eliminate treatment effects).

We obtained information on the following sociodemographic and drug-use characteristics of the participants: age, sex, ethnic background, housing situation (permanent or nonpermanent), sources of income (paid work), illegal sources of income (sex work, drug dealing, other criminal activities), injection drug use in the 30 days before assessment, drug overdose and illicit use of opioids (Demerol, Dilaudid, heroin, methadone from the street, morphine, OxyContin, Percocet, Percodan and Tylenol 3 or 4 ) in the 30 days before assessment. Categorical variables were analyzed with the use of Pearson's $\chi^{2}$ test; continuous variables were analyzed with the use of independent sample $t$ tests and analysis of variance. In the case of unequal variances, the Kruskal-Wallis and median tests were also performed on continuous data. All variables were considered statistically significant if $p$ was less than 0.05 .

Participants were, on average, 35 years of age; most were male and white. Half were not stably housed, and about 2 in 5 had received income from illicit sources in the 30 days before assessment (Table I). Overall, one-third of the total sample reported using heroin during the 30 days before assessment. However, heroin was the most commonly used opioid in only 2 of the 7 study sites (Vancouver and Montréal), reported by about half of the local participants. At 4 of the sites, heroin use was virtually absent. For the majority of participants in these cities, prescription opioids (e.g., hydromorphone, morphine, oxycodone) were the predominant opioids used, in locally different patterns (Table 2). Moreover, the longitudinal analysis suggested that heroin use had significantly decreased in all sites since $200 \mathrm{I}$ (overall effect -24.9\%, $p<0.00 I$ ). Use of cocaine and crack cocaine was also very common across the sites and also decreased over time (-I4.I\% and $-\mathrm{II} .7 \%$ respectively, $p<0.00 \mathrm{I}$ ). Parallel to the above changes, key risk behaviours (e.g., drug injection, needle sharing and overdosing) decreased. For example, injec- 
tion drug use reported during the 30 days before assessment decreased significantly in the total sample between 2001 and 2005 , from $84.5 \%$ to $63.7 \%$ ( $p<0.001)$.

Our data provide evidence that suggests that heroin use has become an increasingly marginal form of drug use among illicit opioid users in Canada, particularly outside of Vancouver and Montréal (port cities that are major heroin import points). Instead, the use of prescription opioids in varying forms has become the predominant form of illicit opioid use. Recent data from the United States have indicated similar

Table 1: Sociodemographic and drug-use characteristics of participants in the OPICAN study who were not receiving methadone maintenance treatment, at 2005 follow-up assessment, by site

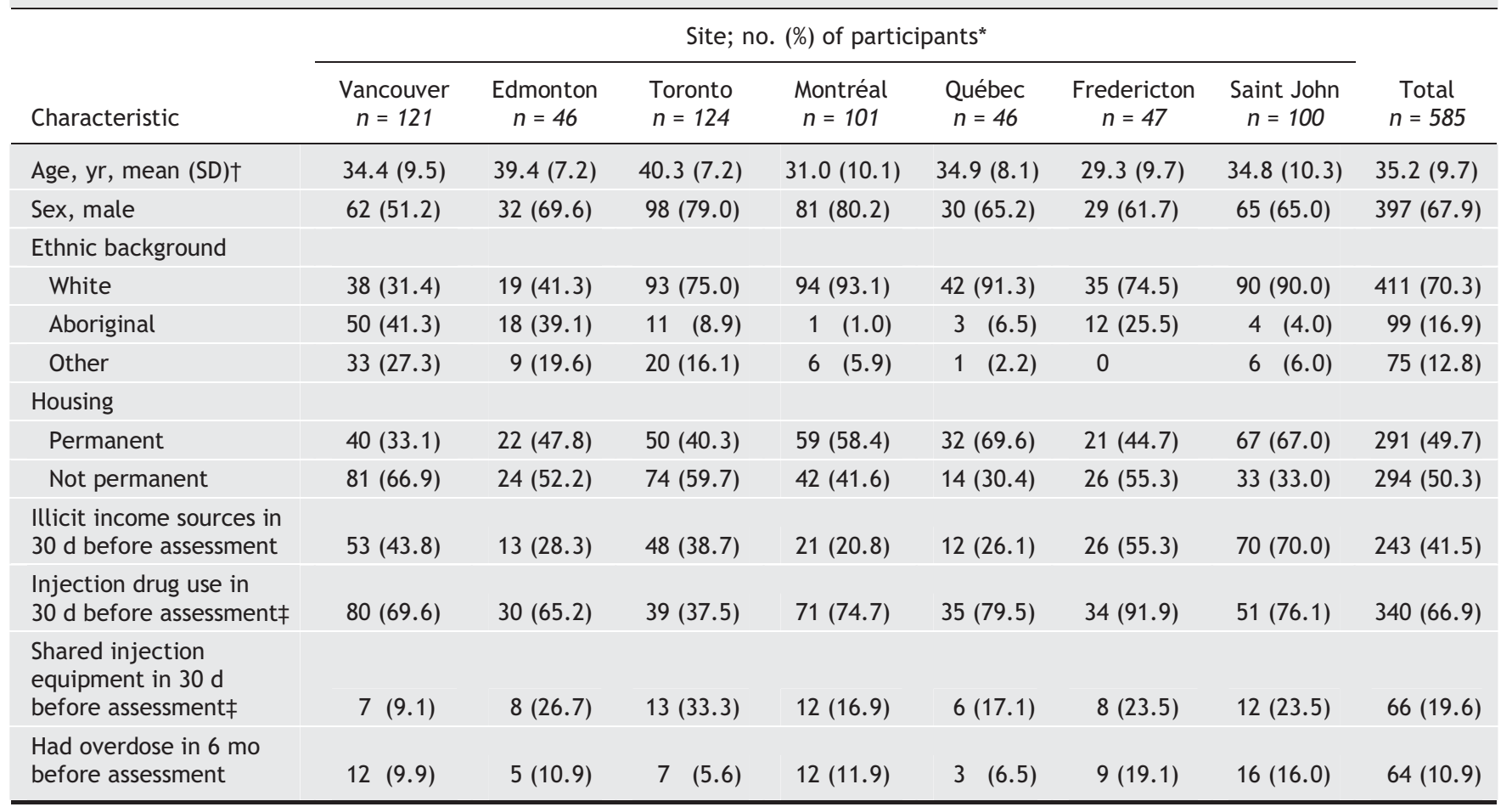

Note: Missing data affect cell counts for some variables. SD = standard deviation.

*Unless stated otherwise.

$\dagger$ Analysis of variance was performed and, because of unequal variances, the Kruskal-Wallis test $\left(\chi^{2}=80.82,6\right.$ degrees of freedom [df], $\left.p<0.001\right)$ and the median test (median $=36 ; \chi^{2}=54.05,6 \mathrm{df}, p<0.001$ ) were also performed.

$\ddagger$ Sample size differs from total $n$ because of missing values.

Table 2: Illicit opioid use by participants in the OPICAN study reported at 2005 assessment, by site

\begin{tabular}{|c|c|c|c|c|c|c|c|c|}
\hline \multirow{2}{*}{$\begin{array}{l}\text { Opioid } \\
\text { Demerol (meperidine) }\end{array}$} & \multicolumn{7}{|c|}{ Site; no. (\%) of participants } & $\begin{array}{l}\text { Total } \\
n=585\end{array}$ \\
\hline & 0 & $\begin{array}{c}\begin{array}{c}\text { Edmonton } \\
n=46\end{array} \\
0\end{array}$ & $9 \quad(7.3)$ & $1(1.0)$ & $3(6.5)$ & $\begin{array}{c}\text { Frederiction } \\
\quad n=47 \\
9(19.1)\end{array}$ & $\begin{array}{l}\text { Saint John } \\
n=100 \\
15(15.0)\end{array}$ & $37 \quad(6.3)$ \\
\hline Dilaudid (hydromorphone) & $6 \quad(5.0)$ & $6(13.0)$ & $24(19.4)$ & $25(24.8)$ & $25(54.3)$ & $43(91.5)$ & $90(90.0)$ & $219(37.4)$ \\
\hline Heroin (diacetylmorphine) & $77(63.6)$ & $4 \quad(8.7)$ & $27(21.8)$ & $55(54.5)$ & $4 \quad(8.7)$ & 0 & $8 \quad(8.0)$ & $175(29.9)$ \\
\hline $\begin{array}{l}\text { Morphine or Ms Contin } \\
\text { (morphine) }\end{array}$ & 10 & $23(50.0)$ & 47 (37.9) & $7 \quad(6.9)$ & $10(21.7)$ & $22(46.8)$ & $12(12.0)$ & $131(22.4)$ \\
\hline OxyContin (oxycodone) & $4 \quad(3.3)$ & $9(19.6)$ & $40(32.3)$ & $1(1.0)$ & $16(34.8)$ & $26(55.3)$ & $35(35.0)$ & $131(22.4)$ \\
\hline $\begin{array}{l}\text { Percocet or Percodan } \\
\text { (oxycodone plus } \\
\text { acetaminophen or ASA) }\end{array}$ & 0 & $6(13.0)$ & $78(62.9)$ & $2(2.0)$ & 0 & $16(34.0)$ & $44(44.0)$ & $146(25.0)$ \\
\hline
\end{tabular}


patterns, including evidence that the rate of prescription opioid abuse has exceeded the rate of heroin use in American household survey populations in recent years. ${ }^{14,15,18}$

Our findings highlight several crucial points. First, prescription opioids used by street drug users originally come from the medical system rather than from illicit production and distribution (as is the case for heroin). Our data on this are limited, but they do indicate that, although the vast majority of cohort participants reported buying their heroin from drug dealers, a substantial proportion of prescription opioids used were obtained directly or indirectly (e.g., through friends or partners) from sources in the medical system (data not shown). The problem of illicitly obtained prescription opioids from medical sources has been repeatedly documented and is currently receiving increased attention in the United States and Australia. ${ }^{15,19,20}$ We cannot determine at this time whether the fundamental shift from heroin to prescription opioid abuse in Canada is driven mainly by demand or supply. However, Canada is the world's top per capita consumer of a number of opioids (e.g., hydromorphone), which makes for an "opioid-rich" environment. ${ }^{21,22}$ Since prescription opioid control measures are lax (especially when compared with measures implemented in the United States) and inconsistent across Canada (only a few provinces have prescription monitoring programs in place), this approach needs to be reconsidered in the interest of prevention. ${ }^{23-25}$ However, such measures should not undermine access to adequate opioid-based pain treatment, which has taken a long time to accomplish..$^{23,26,27}$ Furthermore, a better understanding of illicit opioid users' comorbidity profiles is needed. Many report their prescription opioid abuse as being related to previous exposure to pain treatment or report psychiatric symptoms that are undiagnosed or untreated (e.g., depression), for which their continued drug use may function as "self-medication." ${ }^{28-30}$

Finally, the documented changes in illicit opioid use may require adjustments to opioid addiction treatment programs. Currently available or proposed treatment interventions (e.g., methadone maintenance, buprenorphine maintenance or medical heroin treatment) principally target heroin addiction. ${ }^{11,31}$ The efficacy of these interventions for the growing population of illicit prescription opioid users seeking treatment needs to be validated, or alternative treatment interventions identified.

\section{This article has been peer reviewed.}

From the Centre for Addictions Research of BC, University of Victoria, Victoria, BC (Fischer); the Centre for Addiction and Mental Health, University of Toronto, Toronto, Ont. (all authors); and the Research Institute on Public Health and Addiction, Zurich, Switzerland (Rehm)

\section{Competing interests: None declared.}

Contributors: Benedikt Fischer designed the study, co-developed the analysis plan and data interpretation and was the principal author. Jürgen Rehm codeveloped the analysis plan and contributed to the data interpretation and drafting of the manuscript. Jayadeep Patra executed the data analysis plan and contributed to the data interpretation and drafting of the manuscript. Michelle Firestone contributed to the data interpretation and drafting of the manuscript. All of the authors approved the final version of the manuscript

Acknowledgement: This study was funded by a grant from the Canadian Institutes of Health Research.

\section{REFERENCES}

I. Giffen PJ, Endicott S, Lambert S. Panic and indifference: the politics of Canada's drug laws. Ottawa: Canadian Centre on Substance Abuse; I99I.

2. Le Dain G, chair.Commission of Inquiry into the Non-Medical Use of Drugs. Ottawa: Information Canada; 1972.

3. Health Canada. Reducing the harm associated with injection drug use in Canada. Ottawa: Health Canada; 200 .

4. Cain J. Report of the Task Force into Illicit Narcotic Overdose Deaths in British Columbia. Victoria: Ministry of Attorney General; 1994

5. Remis R. A study to characterize the epidemiology of hepatitis C infection in Canada, 2002. Final report. Ottawa: Health Canada; 2004.

6. Fischer B, Medved W, Kirst M, et al. Illicit opiates and crime: results of an untreated user cohort study in Toronto. Can J Crim 2001;43:197-217.

7. Wood E, Tyndall M, Spittal P, et al. Impact of supply-side policies for control of illicit drugs in the face of the AIDS and overdose epidemics: investigation of a massive heroin seizure. CMAJ 2003;168:165-9.

8. Royal Canadian Mounted Police (RCMP). Drug situation in Canada - 2003. Ottawa: Criminal Intelligence Directorate, RCMP; 2004. Available: www.rcmp-grc gc.ca/crimint/drugs_2003_e.htm (accessed 2006 Sept 2I).

9. Strike C, Gnam W, Urbanoski K, et al. Factors predicting 2-year retention in methadone maintenance treatment for opioid dependence. Addict Behav 2005;30: I025-8.

Io. Anderson J, Warren L. Client retention in the British Columbia methadone program, 1996-1999. Can J Public Health 2004;95:104-9.

II. Ward J, Hall W, Mattick R. Role of methadone maintenance in opioid dependence. Lancet I999;353:22I-6.

I2. Schechter MT. NAOMI - Her time has come. North American Opiate Medication Initiative. JUrban Health 2002;79:I64-5.

I3. Fischer B, Rehm J, Kirst M, et al. Heroin-assisted treatment as a response to the public health problem of opiate dependence. Eur J Public Health 2002;12:228-34.

I4. Cicero TJ, Inciardi JA, Munoz A. Trends in abuse of OxyContin and other opioid analgesics in the United States: 2002-2004. J Pain 2005;6:662-72.

15. Compton W, Volkow N. Major increases in opioid analgesic abuse in the United States: concerns and strategies. Drug Alcohol Depend 2006;81:103-7.

I6. Haydon E, Rehm J, Fischer B, et al. Prescription drug abuse in Canada and the diversion of prescription drugs into the illicit drug market. Can J Public Health 2005; 96:459-6r.

I7. Fischer B, Rehm J, Brissette S, et al. Illicit opioid use in Canada: comparing social, health and drug use characteristics of untreated users in five cities (OPICAN study). JUrban Health 2005;82:250-66.

I8. SAMHSAS Office of Applied Studies. National survey on drug use and health (NSDUH report). Nonmedical oxycodone users: a comparison with heroin users. Washington: US Department of Health and Human Services; 2005.

I9. Martyres RF, Clodes D, Burns JM. Seeking drugs or seeking help? Escalating "doctor shopping" by young heroin users before fatal overdose. Med J Aust 2004;180:2II-4

20. Goldman B. The news on the street: prescription drugs on the black market. CMAJ I998;I59(2):I49-50.

2I. International Narcotics Control Board. Statistical information on narcotic drugs part four. Vienna: The Board; 2004. Available: www.incb.org/pdf/e/tr/nar/2004 /narcotics_part4.pdf (accessed 2006 Oct I7).

22. Fischer B, Rehm J. Illicit opioid use and treatment: challenges for Canada and beyond [editorial]. Can J Psychiatry 2006;51:621-3.

23. Zacny J, Bigelow G, Compton P, et al. College on Problems of Drug Dependence taskforce on prescription opioid non-medical use and abuse: position statement. Drug Alcohol Depend 2003;69:215-32.

24. Health Canada. The regulation of prescription drugs: roles and responsibilities. Ottawa: The Ministry; 2004. Available: www.hc-sc.gc.ca/ahc-asc/media/nr-cp /2004/2004_pharmbki_e.html (accessed 2006 Oct I7).

25. College of Physicians and Surgeons of Ontario. Prescription drug abuse [policy no Io-or]. Toronto: The College; 2002. Available: www.cpso.on.ca/Policies/drug _abuse.htm (accessed 2006 Oct I7).

26. Ballantyne J, Mao J. Opioid therapy for chronic pain. N Engl J Med 2003;349:1943-53.

27. Joranson D, Carrow G, Ryan K, et al. Pain management and prescription monitoring. J Pain Symptom Manage 2002;23:23I-8.

28. Ives TJ, Chelminski PR, Hammett-Stabler CA, et al. Predictors of opioid misuse in patients with chronic pain: a prospective cohort study. BMC Health Serv Res 2006;6:46.

29. Compton P, Darakjian J, Miotto K. Screening for addiction in patients with chronic pain and "problematic" substance use: evaluation of a pilot assessment tool. J Pain Symptom Manage i998; $16: 355-63$

30. Khantzian E. The self-medication hypothesis of substance use disorders: a reconsideration and recent applications. Harv Rev Psychiatry I997;4:23I-44.

31. National Institute on Drug Abuse. Principles of drug addiction treatment: a research-based guide. Bethesda (MD): The Institute; I999. Available: www.nida.nih .gov/PODAT/PODATindex.html (accessed 2006 Sept 2I).

Correspondence to: Dr. Benedikt Fischer, Centre for Addictions Research of BC, University of Victoria, Rm. I24, Technology Enterprise Facility, PO Box 1700 Stn CSC, Victoria $B C$ V8W $2 Y_{2}$; fax 250 472-532I; bfischer@uvic.ca 